note that prolonged survival has been reported after extended resection in a case of colonic

1 Wanke M, Schwan $H$. Pathology of gastric cancer. World $\mathcal{f}$ Surg 1979; 3: 675-84.

2 McNeer G, Sunderland DA, McInnes G, et al. A more thorough operation for gastric cancer; anatomic basis and description of technique. Cancer 1951; 4: 957.

3 Remine WH, Gomes MMR, Dockerty MB. Long term survival (10 to 56 years) after surgery for carcinoma of survival (10 to 56 years) after surgery
stomach. Am $₹$ Surg 1969; 117: $177-84$.

4 Papachristou DN, Shiu MH. Management by en bloc multiple organ resection of carcinoma of the stomach multiple organ resection of carcinoma of the stomach invading

483-7.

5 Korenaga D, Okamura T, Baba H, Saito A, Sugimachi K. Results of resection of gastric cancer extending to adjacen organs. Br $\mathcal{f}$ Surg 1988; 75: $12-5$.

6 O'Hare PM, Leonard AG. Reconstruction of major abdominal wall defects using the tensor fasciae latae myocutaneous flap. Br $\mathcal{F}$ Plast Surg 1982; 35: 361-6. cancer requiring abdominal wall reconstruction. ${ }^{11}$

7 Neven P, Shepherd JH, Tham KF, Fisher C, Breach N. Reconstruction of the abdominal wall with a latissimus dorsi musculocutaneous flap: a case of a massive abdominal wall metastasis from a cervical cancer requiring palliative resection. Gynecol Oncol 1993; 49: 403-6.

8 Olearchyk AS. Gastric carcinoma. A critical review of 243 cases. Am $¥$ Gastroenterol 1978; 70: 25-45.

(abs. Am g Gastrontero Abramovich IaA, Bul 'vakhter LA, Kripal 'skii LN. [A case of metastatic cancer en cuirasse of the skin in stom

10 Choi HM, Myung KB, Kook HI. Cutaneous metastatic adenocarcinoma of stomach-nodular and inflammatory carcinoma. $\mathcal{F}$ Korean Med Sci 1986; 1: 49-52.

11 Gardner B. Five-year survival after extended resection of colon cancer. $\mathcal{f}$ Surg Oncol 1987; 34: 258-61.

\title{
Fatal bronchospasm after oral ingestion of isphagula
}

\author{
DC Hulbert, PJ Thorpe, AJ Winning, MW Beckett
}

\section{Summary \\ We report the case of a 40-year-old asthmatic who suffered fatal broncho- spasm following oral injestion of a lax- ative containing isphagula.}

Keywords: asthma, bronchospasm, isphagula

We describe a case of fatal bronchospasm following oral ingestion of isphagula. It is well established that bronchospasm associated with occupational asthma can occur after inhalation of isphagula and that anaphylaxis can occur after oral ingestion of isphagula and psyllium. However, fatal anaphylaxis after oral ingestion of isphagula has never been reported.

\section{Case report}

West Middlesex

University Hospital,

Twickenham Road, Isleworth, Middlesex

TW7 6AF, UK

Department of

Accident and

Emergency

DC Hulbert

MW Beckett

Department of

Pathology

PJ Thorpe

Department of Chest

Medicine

AJ Winning

Accepted 16 November 1994
A 40-year-old man, known to be asthmatic, was taken to the Accident and Emergency department as a priority call. He was first diagnosed as being asthmatic in 1986 and his symptoms were controlled with inhaled salbutamol and beclamethasone diproprionate.

He had had two previous hospital admissions, the first precipitated by the ingestion of a single tablet of aspirin, the second by ibuprofen. On both occasions he had severe bronchospasm requiring admission to the Intensive Care Unit, although ventilation was not required.

According to his wife, the evening prior to admission he had felt wheezy and had taken nebulised salbutamol at home.
In the morning he had no respiratory symptoms but had taken Fybogel as he had been unable to open his bowels for several days. $\mathrm{He}$ had previously taken this with no abnormal sequaelae. When his wife left for work at $07.15 \mathrm{~h}$ he was entirely well. Following the ingestion of one sachet $(3.5 \mathrm{~g})$ between $07.30 \mathrm{~h}$ and $09.30 \mathrm{~h}$ he became acutely short of breath and was noted by his family to be wheezy. $\mathrm{He}$ took nebulised salbutamol which had no effect and an ambulance was called. He then had a cardiorespiratory arrest and, in spite of full resuscitative measures in the Accident and Emergency Department, he died at $11.00 \mathrm{~h}$.

At post-mortem examination the epiglottis and larynx were normal; the upper airways contained a small amount of mucus and the lungs were found to be severely congested with blood with evidence of acute pulmonary oedema. It was thought that these findings were consistent with acute hypoxia due to sudden onset of severe bronchospasm.

\section{Discussion}

Fybogel is a laxative preparation, the main constituent being isphagula husk. This itself is derived from the dried seeds of Plantago ovata, and there is evidence that this can induce asthma, bronchospasm, and even anaphylaxis. ${ }^{1}$

Psyllium (USP) which is used as a laxative in America is derived from a combination of the dried seeds of Plantago ovata and Plantago psyllium and this has also been shown to cause bronchopasm.

Sensitisation probably occurs through 


\begin{tabular}{|l|}
\hline Learning points \\
\hline - oral ingestion of isphagula may cause fatal \\
bronchospasm \\
- significant sensitivity to laxatives must be \\
recognised \\
\hline
\end{tabular}

inhalation of the powder and has been demonstrated in those individuals who suffer longterm exposure, usually employees in manufacturing plants and healthcare workers. Marks ${ }^{2}$ demonstrated that $7.6 \%$ of employees in an exposed workforce were allergic to isphagula. Symptoms were particularly referrable to the upper airways. There is one report of a previously sensitised nurse suffering severe anaphylaxis after ingesting a bowl of psylliumcontaining cereal, ${ }^{3}$ and three cases of milder symptoms in individuals who took prescribed psyllium-containing laxatives. ${ }^{4,5}$ There have

1 Gillespie BF, Rathburn FJ. Adverse effects of psyllium. Med Assoc $¥ 1992$; 146: 16-7.

2 Marks GB, Salome CM, Woolcock AJ. Asthma and allerg associated with occupational exposure to isphagula and senna products in a pharmaceutical workforce. Am Rev Respir Dis 1991; 144: 1065-9.

3 Drake CL, Moses ES, Tandberg D. Systemic anaphylaxis after ingestion of a psyllium-containing breakfast cereal. $A m$ 7 Emerg Med 1991; 9: 449-5 been no previous reports of Fybogel-associated death.

This patient had no exposure to nonsteroidal anti-inflammatory drugs on the day of the fatal episode, but the post-mortem findings are consistent with rapid onset of fatal bronchospasm, since the classical findings in asthma of enormous dilatation of the lungs with air and the presence of tenacious mucus plugs were absent. This implies that the patient's asthma was quiescent at the time. Although uncommon, the possibility of allergy to seemingly harmless laxatives should be recognised. It is not known whether sensitivity to aspirin and non-steroidal anti-inflammatory drugs is associated with sensitivity to laxative substances. In particular, patients who have ingested isphagula previously are at risk of becoming sensitised and thus developing severe bronchospasm due to anaphylaxis.

We have reported this case to the Committee on Safety of Medicines via the yellow card system.

4 Lantner RR, Espiritu BR, Zumerchik P, Tobin MC Anaphylaxis following ingestion of a psyllium-containing cereal. $\mathcal{F} A M A$ 1990; 264: 2534-6.

5 McConnochie K, Edwards JH, Fifield R. Isphagula sensitisation in workers manufacturing a bulk laxative. Clin Exp Allergy 1990; 20: 199-202. 